\title{
Becoming a Maker Pedagogue
}

\author{
Exploring Practices of Making and Developing a Maker Mindset for Preschools
}

\author{
Sophie Landwehr Sydow \\ Stockholm University (DSV) and \\ Södertörn University (NMT) \\ Stockholm, Sweden \\ sophie@dsv.su.se
}

\author{
Anna Åkerfeldt \\ Stockholm University, Department of \\ Mathematics and Science Education \\ Stockholm, Sweden \\ anna.akerfeldt@mnd.su.se
}

\author{
Per Falk \\ Kvasar Makerspace \\ Sundbybergs Stad \\ Stockholm, Sweden \\ per.falk@sundbyberg.se
}

\begin{abstract}
Making has with its mindset and hands-on agenda found ways into all levels of education. From primary school to higher education, in after-school curricula and public places of learning, making has made a considerable impact. In early childhood education, teachers and their professional development are however less in focus. We present a municipality-driven project of training nine preschool teachers with a maker mindset. Our data builds on teachers' experience and practice, shared in two workshops and $16 \mathrm{blog}$ posts. The pedagogues' reflections of their own and learners' actions make way for how 'making' impacts them as educators. We use Resnick's four P's: Projects, Peers, Passion, Play and contribute Places and Presentation as additional elements of creative learning. We show that developing a maker mindset entails openness, curiosity, cocreation, responsiveness and the willingness to include technology and materials into professional practice, which is key towards becoming a maker pedagogue.
\end{abstract}

\section{CCS CONCEPTS}

- Applied computing $\rightarrow$ Education; • Human-centered computing $\rightarrow$ Empirical studies in $\mathrm{HCI}$.

\section{KEYWORDS}

maker pedagogue, early childhood education, maker mindset, makerspace, four P's, creative learning, municipality makerspace

\section{ACM Reference Format:}

Sophie Landwehr Sydow, Anna Åkerfeldt, and Per Falk. 2021. Becoming a Maker Pedagogue: Exploring Practices of Making and Developing a Maker Mindset for Preschools. In FabLearn Europe / MakeEd 2021 - An International Conference on Computing, Design and Making in Education (FabLearn Europe / MakeEd 2021), June 2-3, 2021, St. Gallen, Switzerland. ACM, New York, NY, USA, 10 pages. https://doi.org/10.1145/3466725.3466756

\section{INTRODUCTION}

Children growing up today are surrounded by and have access to digital technologies daily. They are often early adopters of new technologies and moving seamlessly across analogue and digital

This work is licensed under a Creative Commons

Attribution-NonCommercial-NoDerivs International 4.0 License.

FabLearn Europe / MakeEd 2021, June 2-3, 2021, St. Gallen, Switzerland

(c) 2021 Copyright held by the owner/author(s).

ACM ISBN 978-1-4503-8989-1/21/06.

https://doi.org/10.1145/3466725.3466756 environments and materials. The use and omnipresence of digital technologies draws the attention to development of children's digital literacy and the knowledge to "...navigate a complex technological world, and contribute to social, economic and cultural developments" as Marsh and colleagues point out [34, p. 221]. However, early childhood education seems to struggle with the demands that children's already lived reality proposes and is challenged by taking the necessary steps towards pedagogical transformation. These include the demand to adequately develop children's digital literacy skills $[32,41,50]$ as well as make way for computational thinking [1, 7, 24, 28]. Here, for example Räisänen [42, p. 15] points out that educators should "strive for change concerning not only the modes or contents of literacies, but also the structures of education in classroom communities". In particular the change from traditional practices and teacher directed instruction to new kinds of social spaces, is described as difficult [27], which in return require addressing the professional development of teachers. In recent years, researchers within Human-computer interaction (HCI), education research, didactic and library studies among others, have investigated if and how influences of the maker movement could be a way to transform education [e.g., 10, 19, 26, 34, 35, 48]. This has foremost taken place through the establishment of makerspaces as learning environments [e.g., 9, 16, 40, 51, 54, 57] as well as a rediscovery of hands-on practice and learning-by-doing [2, 13, 55]. Kafai states that educators have different experiences in making, which "requires professional development that not only addresses technical proficiency but also builds a failure mindset, social competencies, and community connections" [26, p. 5]. In this paper we describe how a municipality-driven makerspace took on this project and we reflect on what it entails to become a maker pedagogue in the first place. Here a makerspace was formed to address these challenges by starting a process that involves preschool teachers who become maker pedagogues. Here we approach pedagogical transformation by using a maker mindset to address and to build on preschool tradition instead of starting from a technology perspective. The following three research questions have guided the study:

- What does it entail to become a maker pedagogue in preschool education?

- What are the opportunities and challenges maker pedagogues face?

- In which way can municipality makerspaces support maker pedagogues practice?

For this paper we analyzed two workshops with maker pedagogues and 16 blog posts they wrote, which resulted in close readings of 
the preschool teachers' experience and practice. We put the resulting data in relation to meta-observations of ongoing activities that we discussed on a monthly basis. In the analysis, we made use of Resnick's framework of the four P's (Projects, Peers, Passion, Play) of creative learning $[44,45]$ which is informed by his previous work $[25,43]$ to both structure our data, but that also initially informed the maker pedagogues practice. We contribute two additional P's that emerged from the data: Places and Presentation that impacted the pedagogues' work and that add to a more situated understanding of creative learning. In the concluding discussion, we then highlight certain characteristics of the maker pedagogues as seen in our findings and turn towards the opportunities and challenges that the group shared and reflected upon. Further we discuss the importance of a working infrastructure to shape similar spaces and communities that make it possible to spread a maker mindset.

\section{BACKGROUND}

Making has in recent years gained momentum, as a niched research field in its own right [46] but in particular made an impact in education: both in regards to teaching and learning. Makerspaces are often connected to informal learning spaces and extracurricular activities, thus in recent years become more common in formal educational settings as well. Foremost there has been an interest in STEAM-subjects to adapt [14, 18, 22, 30, 37], further by making use of design thinking $[11,33]$, hands-on tinkering $[6,8,36]$ and towards experiential learning $[15,23]$. Approaches to material understanding [59] and different literacies from learning or maker contexts such as digital- [50], media- [27] or material literacy [31] contribute with opportunities for teachers to introduce digital practices, combined with manufacturing tools, craft and aesthetic thinking. Here we see that 'making' in the context of preschools and early childhood education is particularly interesting to investigate. While creativity, play and aesthetic work are foregrounded already - technology and emergent materials are not fully addressed nor integrated into preschool education in Sweden. Hence a lot of the research on technology within early childhood education has been focused on the use of iPads [e.g., 3, 28, 53] others for example foreground digital reading in the preschool [20], teaching mathematics through digital tools [29] and digital play [38]. In this paper we approach the integration of technologies from a wider perspective and not just focus on screen-based applications and the interface between child(ren) and the screen. We want to move the discussion towards creativity, problem-solving, innovation and making where technologies are in a sense in the background that facilitates these processes. While this broader agenda has been picked up by many scholars from a diverse range of fields that witness the interest in education for making, there are few who have explored making in the context [e.g., 12,17,56] and in connection with the professional development of preschool teachers [e.g., 4, 21, 39]. Some examples we want to highlight are Marsh et al. [34] who state that makerspaces contribute to early childhood settings and argue that they lead to the development of skills and knowledge increasingly important for highly technologized societies. Here the scholars identified concepts of maker agency, maker funds of knowledge and postdigital maker play (where traditional and digital play co-exist).
In other work, Scott and Wohlend [49] introduce maker literacies, here highlighting the makerspace as a place that allows for new forms of literacy that emerge through encounters of digital media and manufacturing technologies. They argue that learners and teachers are best supported by 'playshop models' and the inclusion of play-enriched maker literacy curricula that empowers children's creativity to collaboratively engage with the new materials and tools [49, p. 217]. Also relevant is Becker and Jacobsen [5] who have used a makerspace and a design based research approach as context to rethink curriculum together with a teacher (active in grade six however). Through "engaging with curricular designs for making, the enactment of designs in the makerspace, and reflections on the learning that occurred using an interactive process which affected her planning, acting and evaluating were reciprocally related and integrated; in short, Riley [the teacher] was approaching curriculum as praxis vs. curriculum as content" [5, p. 9]. Hence, Becker and Jacobsen findings show that becoming a 'maker teacher' and teaching with a maker mindset changed a teachers' professional pedagogical practice. Frameworks around creative learning and the competences that new materials require, impact how futureoriented educators need a way to work and navigate this fast-paced technological development and what it brings about. Literature in this context is scarce, therefore this paper tries to contribute in narrowing this gap. As the demand in current society impacts and strengthens especially preschool teachers' and children's agencies to affect how to make use of technology, not only to receive and use it - we see an opening and particular value in taking this route.

\section{THE MAKERSPACE: A CASE DESCRIPTION}

The makerspace this paper focuses on is in the northern outskirts of a Swedish city, initiated and financed by a local municipality with 50000 inhabitants. Currently, 27 preschools with 600 pedagogues work and 6000 children are learners in these preschools. The municipality is in a phase of urban expansion, with extensive growth which is a challenging process and affects several functions that the municipality caters to.

\subsection{Setting the Scene}

When the curriculum for preschools was changed in 2018 [52] and the Swedish national strategy for digitalization came into place, there was a consensus in the present management of this municipality to make changes in order to meet the new demands in the curriculum in regards to digital competence. Hence a decision was made to set up a physical place where pedagogues from all municipality preschools could develop competence through hands-on practice. The makerspace opened in 2019 and has since acted as a space where educators meet, share skills and that overall acts as role model, inspirational platform and resource. While the main agenda of the makerspace and the project we highlight here is - the development of an entry point for making in education by training maker pedagogues - this makerspace also acts as a learning platform for university education (such as for the preschool teacher program) and a research hub, furthermore as a test bed for the municipality to try and evaluate pedagogical material from commercial partners. First and second authors of this paper identify as collaborators from 
academic research - also called 'critical friends', while third author is the makerspaces project leader acting reflective practitioner.

\subsection{Making as Professional Development}

Professional development from a lifelong-learning perspective needs to be addressed in a different way than visiting a course that lasts for a couple of weeks and then applying skills learned in the workplace. As technology and societal change is fast paced, continuous professional development is needed. Moreover the community created acts as an important resource in this development. Here Wenger-Trayner et al. argue: "From a social perspective we see the real 'body of knowledge' as a community of people who contribute to the continued vitality, application, and evolution of the practice" [58, p. 13]. Therefore the training of the pedagogues was designed to cater both progress and continuum. It was decided to train one pedagogue from each preschool unit, who spent between 5-20 percent of their paid teaching time to take part in makerspace activities and accordingly impact work within the units. Hence maker pedagogues act as ambassadors, which also minimized the distance between overall aim and their colleagues. Influenced by Learning Creative Learning (LCL) approaches, the modules of the different workshops and activities were aimed at 'learning to think creatively' and work with Resnick's principles around four P's [45] In monthly workshops overall themes were discussed, and the pedagogues were asked to reflect and frame their experience in this new context as maker pedagogues. Additionally the makerspace acted as a resource, so the pedagogues made use of the physical and digital materials available to them. All maker educators also had access to personal supervision, a small own budget and keys to the makerspace, thus sharing a responsibility for the space and all its resources. Finally the maker pedagogues could find opportunities to influence ongoing teaching activities and transform learning environments of their own units.

\section{METHOD AND STUDY STRUCTURE}

Over the duration of 15-months, we have followed the training of a group of nine preschool teachers. During 2020, the preschool teachers took part in 10 workshops to think about and develop their profession in relation to becoming maker pedagogues. Our findings are close readings of the preschool teachers' experience and practice that they shared in two of these workshops, which is the primary source for this paper. Furthermore, we analyzed a selection of 16 blog posts as secondary data, where the maker pedagogues reflected on their ongoing practice. This selection of blog posts featured notions that included personal reflections of the decisions and progress pedagogues made. Here we wanted to ensure that we collect different voices from the group that act representative for the groups' achievements and concerns, also highlighted in discussions in the workshops. By combining primary and secondary data in this way we gained insights on how maker pedagogues reflect in more closed settings but also how lessons-learned were reflected upon when shared with the larger public.

\subsection{Workshops}

The two workshops (WS) were held through a video conference system due to the Covid-19 situation. The number of participants and activities varied in the workshops. At WS1, in June 2020, two maker pedagogues, the project leader, and one of the researchers attended. At WS2, in November 2020, five maker pedagogues, the project leader, and the both researchers were present. The meetings lasted for approximately two hours each. Overarching purpose of the two workshops was to discuss the work with the children at their units and to verbalize and discuss maker activities. The two workshops were recorded and transcribed, (which resulted in 106 pages of transcription) and were analyzed through the lens of Resnicks four P's which will be described in section 4.3. The first workshop (WS1) observed took place at the end of the preschool years' annual term and was a concluding session where the maker pedagogues described and discussed their maker activities during the year. Here the workshop topic was based on the relation between fun and learning. The second workshop (WS2) was focused on maker activities that were failures and successes and the participants were prepared to share examples. The overall purpose of WS2 was to get to grips with the practice that the maker pedagogues take for granted, i.e. how they present material to the children, how they behave with the children, how they talk to and about children and their own views on the rhetoric used.

\subsection{Blog Posts}

As secondary data, we then analyzed 16 selected blog posts that provide a broader illustration of the different projects that the maker pedagogues engaged and referred to during the WS discussions. Underlying source for this material was the documentation of the ongoing work that were communicated on a shared blog. The makerspace project has both a blog and an Instagram feed where the purpose is to document, package and distribute insights, tips and shared materials to all employees in the municipality but which also aims at the broader public. This blog has developed into a natural channel for both maker pedagogues to document their projects and progress, as well as to write about the development and ongoing work. For this paper, we selected 16 blog posts by five of the nine active maker pedagogues published between December 2019 and February 2021. The overarching website, including the blog and the projects' Instagram feed are curated and edited by the project leader. For the analysis, we transferred and analyzed the blog posts with help of the web based digital workspace application Mural, as face-to-face meetings were prohibited due to the Covid-19 restrictions. By using annotating tools, we tagged and commented on both text- and visual material that the maker pedagogues shared. The selected blog posts were all written by maker pedagogues and shared personal reflections on their role and progress as maker pedagogues.

\subsection{Analytic Approach}

One of the pedagogical frameworks that the municipality makerspace uses is Resnick's [44, 45] work with the four Ps' (Projects, Passion, Peers, Play) and the notion of Low Floors, High Ceilings, and Wide Walls which were used as a starting point to address the pedagogues different experiences. The four P's of creative learning fit well as a working and pedagogical approach for both maker and preschool educators who engage with creative processes with children. The four P's describe 1) Projects: People learn best when 
they are actively working on meaningful projects, when they generate new ideas or design iterative prototypes 2) Peers: Learning flourishes as a social activity, with people sharing ideas, collaborating on projects and building on each others work; 3) Passion: When working on projects people care about, they work longer and harder, persist in the face of challenges and learn more in the process and finally 4) Play: Learning involves playful experimentation, that includes trying new things, tinkering with materials, testing boundaries, taking risks and iterating again and again. What is important to point out is that the approach builds on creative learning that originates from a digital context working with Scratch. In our paper, we made use of the four Ps' as analytical framework to structure our data and to ask following questions (see table 1) that provide access to the maker pedagogues' experience in practice.

Table 1: Initial themes and questions that guided analysis.

\begin{tabular}{l|l} 
Theme & Questions \\
\hline Projects & $\begin{array}{l}\text { How is the work process described? Are projects } \\
\text { meaningful and in which way? }\end{array}$ \\
\hline Peers & $\begin{array}{l}\text { Are ideas being shared? If so, in what way? How } \\
\text { can the collaboration be described? Do they build } \\
\text { on others' knowledge, if so in what way? }\end{array}$ \\
\hline Passion & $\begin{array}{l}\text { How does enthusiasm and curiosity come in? Can } \\
\text { challenges be traced in the empirical material? }\end{array}$ \\
\hline Play & $\begin{array}{l}\text { How can playfulness be described? Are they taking } \\
\text { risks? Testing boundaries? }\end{array}$ \\
\hline
\end{tabular}

Here they were acting as overarching themes, which provided a first thematic structure of the data. At the same time, we did not limit our analysis to these four themes, but highlighted other things as well. Analysis followed a structured qualitative approach, which still made way and opened for unexpected findings. The reason we chose to combine empirical material from primary sources (the workshops) and secondary sources (the blog posts), was that they together provide a nuanced representation of the maker pedagogues' process of becoming, which is still undergoing. While they share examples from practice in the workshops that are often situated and discussions arise in conversation with each other, the blog posts present more curated reflections on the individual process and progress over a longer period of time. We see that gathering insights from multiple sources helps us to create a more balanced and true representation of the maker pedagogues' actions and reflections.

\subsection{Limitation and Ethical Consideration}

As apparent the paper presents a small qualitative study that addresses research questions in an emerging field, which makes it difficult to generalize findings. Results need to be interpreted in the light of the limited number of following workshops (two out of ten). In our study we have not used instruments for assessing the progress towards becoming a maker pedagogue which may have strengthened the study (see for example a study by [47] where they have deployed assessment instruments with a baseline - in the beginning of the teacher training and a post training measure at the end). As we are foremost interested in the process rather than achievement and progression, we argue that our study makes way for tendencies towards that goal. For this paper, we have made efforts to act transparent in our roles as researchers and 'critical friends' of the makerspace. Along these lines, written informed consent was distributed and signed copies were collected among the participants. Even though they had given already written consent to participate in the maker pedagogue project, which included transparent communication and participation in the projects' different channels, the researchers always informed and asked at the beginning of both WS if it was okay that the session was recorded. Here participants had the option to opt-out at anytime. As we reflect on the maker pedagogues' work and progress as a group and refer to all individuals with an alias.

\section{FINDINGS}

In the following sections, we show and visualize how the four P's impact maker pedagogues work. Additionally, when analyzing the material, two additional P's played an important role in the observed practice and reflections - namely Places and Presentation - which are introduced in section 5.5.

\subsection{Projects}

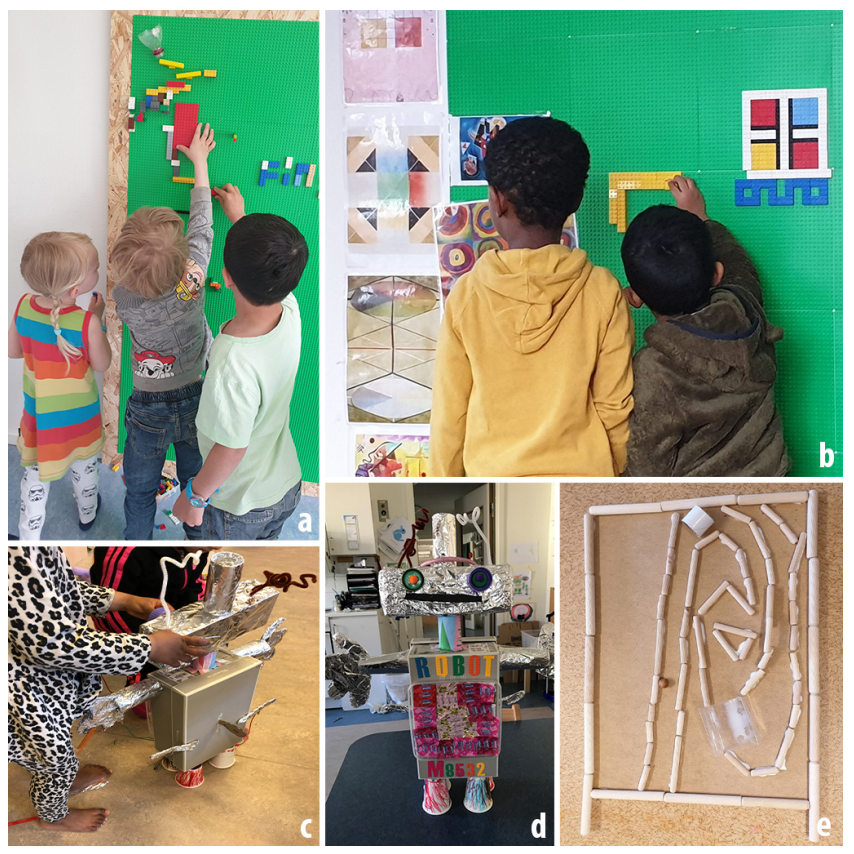

Figure 1: Different projects: (a) Learners building a marble run at the LEGO wall (b) Learners reproduce artworks by af Klint and Kandinsky in LEGO (c) Playing with the robot (d) The DIY robot project (e) Building a maze and testing designs in other materials.

Projects and project-oriented work is key when it comes to a maker mindset as it focuses the attention on an agenda and target, that often combines multiple materials, tools and approaches 
resulting in artifacts, systems or products that makers are interested in. In our data we found multiple projects described which directly involve learners at the preschools. However, there are also several projects that are developed and driven by the pedagogues that not directly included learners, these are instead related to introductory learning of the tools themselves (such as learning to use a 3D printer or exploring LEGO WeDo), exploring different approaches of making (such as working with e-textiles and designing prototypes) as well as testing created learning environments that learners can engage with. One example that is highlighted often is the project of building a LEGO wall [fig. $1 \mathrm{a} / \mathrm{b}$ ]. Here large green LEGO plates are attached to a wall surface, which then creates a platform for learners to build and construct vertically. Maker pedagogue Anette shares how the learners were eager to explore it right away, but involving other pedagogues from the preschool was difficult. Anette reflects: "LEGO is a well-known material for both children and adults and thus a 'harmless' material. Perhaps this can attract colleagues to be more present in the room. The focus is removed from the digital, which can be intimidating, and placed on creativity and construction" (B5). By focusing on one clear, meaningful project and using "known" and approved materials, this maker pedagogue used the LEGO wall project as a stepping stone to ease the way into more digital or advanced projects. On a later occasion, Anette further reports on the progression with this project. In B7 she describes how her learners use the platform to experiment for example with a vertical marble run [fig. 1a]. In another attempt (reported in B14) Anette explores how learners can be influenced by art to heighten abstract thinking through "known" materials in a different setting. Here she includes a small group of learners to copy artworks by artists af Klint and Kandinsky, to "broaden the walls' use and the possibilities it provides", here "an idea was born to highlight classical art and mix aesthetics and technology" [fig. 1b]. She further reflects: "I think the idea of mixing materials is exciting and something that fits into the idea we maker pedagogues work with- to present several materials and tools to solve problems" (B7).

In both workshops the groups talk about projects involving individuals, pairs and groups of learners that interact with the materials that educators introduced. In WS1 pedagogues describe that a project often starts with one or two learners and ultimately grows as other children get curious and interested in the work, by wondering "what is going on" and are then quick to participate. Examples of projects that included this are the robot [fig. 1c and 1d] and the maze projects [an example in 1e]. When describing projects, the maker pedagogues talk about them as ongoing, iterative processes: sometimes without distinct start or ending points. Maker pedagogue Karin states that the robot project continued even after it was "finished" as the children included the result in their play [fig. 1c] and repaired the robot even after breaking. Other projects similarly evolve, such as Karin's project on 3D printing connectors for wooden train rails [see fig. 4a]. However, there are exceptions: The maze project [fig. 1e] for example started off with an assignment from the maker pedagogue instead. Overall, the different examples show how important project-oriented work and the related mindset for the maker pedagogues are as a way to find into their roles.

\subsection{Peers}

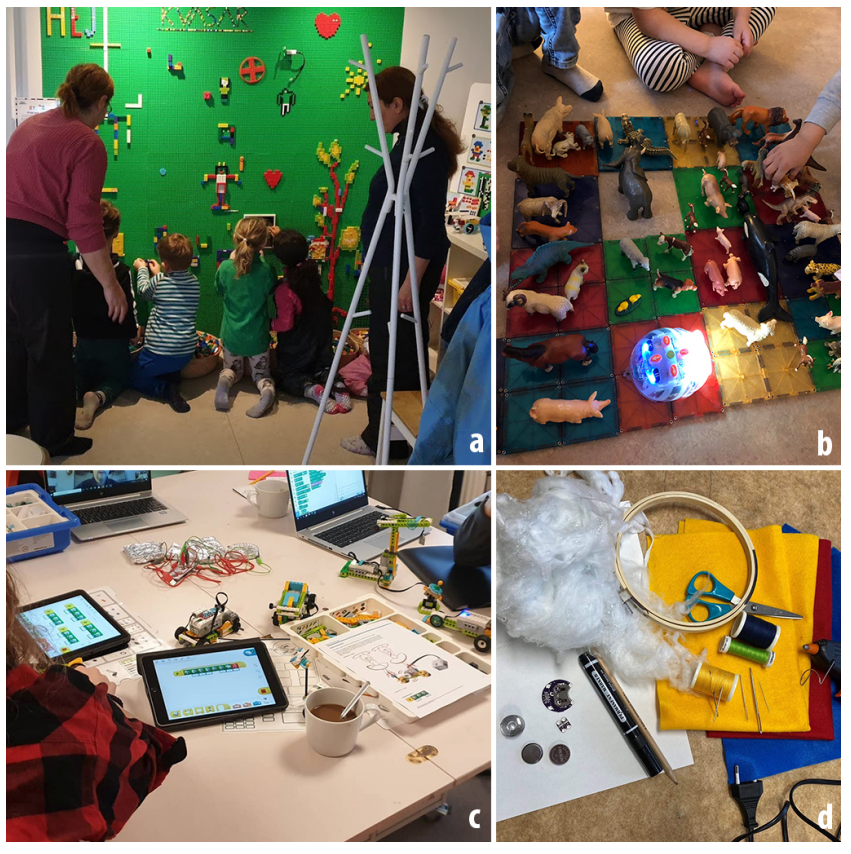

Figure 2: Peers can be learners and pedagogues: (a) Peerlearning in action (b) Learners act as peers combining beebots, magna tiles and toy animals (c) Collaborative peer learning between pedagogues, here concerning LEGO WeDo (d) Material e-textile prep and how-to instructions on the blog, for other maker pedagogues to take after.

Resnick [36] argues that most of the thinking in creative learning is done together with others and in the collaborative making of things [see fig. 2a]. From the analyzed material, three levels of peer learning emerge: 1) between the pedagogues [see fig. 2c] 2) between the pedagogues at their preschools and 3) the pedagogues' description of peer-learning between the learners [as seen in 2b]. In WS2 when the group shared failures, Robin, for example says that she needs to re-design and re-think about how an activity should be designed, where discussions in the group assist. Sharing and talking about their work and support from others help them developing their practice. Instances of building upon each other's ideas are present in our empirical material, such as Karin's explorations with the 3D printer inspire others in the group to try similar projects or Kim's experiments with e-textiles, motivates others to take after [see fig. 2d]. Our analysis shows that the pedagogues are willing to share, present and build upon another work and ideas which leans towards a make-it-together approach [36]. In the workshops, we see that the pedagogues are curious about each others projects and eager of sharing experiences and ideas. Here Robin says: "I want to talk more with you Karin and let you inspire me!" (WS2). Kim explains that when she feels the support from the colleagues "there is space for my creative thoughts and my way of expressing myself" (WS2). Further, Kim also mentions the camaraderie she feels when her colleagues expressed support and interest in her 
"crazy projects". In B6, we see how Kim reflects that changes she brings to her workspace affects also how different units of the preschool may collaborate and work together. Opposite reactions of unwillingness of her peers described Anette in B5: Despite attempts to motivate her preschool colleagues in engaging with the learning environments she created and projects she initiated, there was a lack of engagement. Together the group then discussed different solutions to her experienced dilemma. Hence Anette decided to work with three focused work areas with low thresholds which later made more advanced projects possible. Overall the data shows important insights on how the maker pedagogues acted as peers themselves and supported each other [such as shown in 2c] and how they acted as role models to the peers (children and colleagues) in their preschools.

\subsection{Passion}

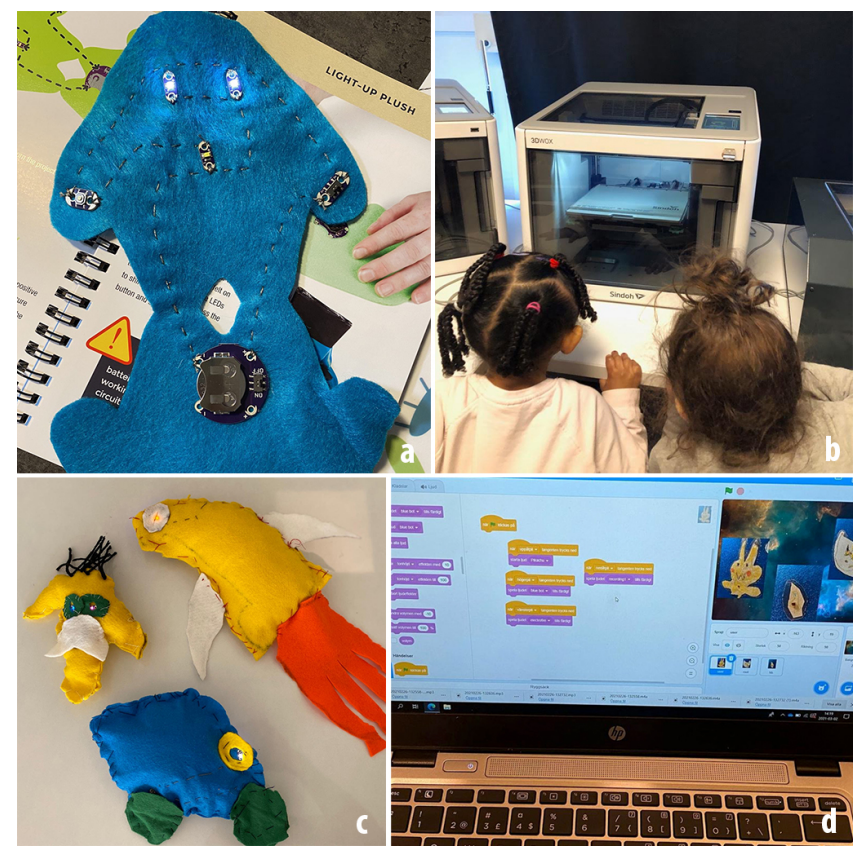

Figure 3: Passion for and in projects: (a) Kim's sewing project with conductive thread (b) Passion for machines: introducing a 3D printer into preschool contexts and finding areas of use (c) Learners e-textile projects showing a ghost, a rocket and a vehicle (d) Passionate projects such as a Pokémon wall activated with MakeyMakey and programmed in Scratch.

Passion is a driving force which builds on foremost needs and interest from a group of individuals or one single individual. Resnick (2017) means if these would be allowed to grow and develop they need access to materials, both digital and analogue, and to other people "who can inspire and support them as they develop creative projects." (ibid, p. 61). Both, in the workshops and blog posts we see how personal interest and motivation is a leading factor for the maker pedagogues success with their overall assignment. In B15 we follow Kim, who shares a detailed account of how she approaches e-textiles and introduces it to her workplace. Kim recalls: "My first thought was, Fun! But it must be very challenging! What if I fail? When sewing with electricity with the children, I first have to know how it works". Passion and a previous interest act as driving forces at the start, but through getting to know electronics, conductive wires and sensors, her repertoire grew quickly through learning-bydoing [see fig. 3a]. She accordingly describes how learners from her preschool picked up the topics she introduced, which resulted in longer and more elaborate creative projects such as with e-textiles [fig. 3c] or a Pokémon inspired interactive wall [fig. 3d]. In WS2 pedagogues describe their passions through the way they address and talk about failures or less successful projects. Failures are described as instances for opportunities to further explore a problem. The pedagogues positioned themselves as co-creators which entails different explorations, intentions and plans. From the analysis we see that the pedagogues struggle with presenting failures: Stina, who reflects on not being proud of a project admits "you are however learning all the time" (Stina, WS2). In the same conversation, Anette makes a connection to her colleagues from the preschool and says that sometimes the discussion gets stuck because of insecurities and an idea that answers could be right or wrong which leads to a defensive reaction. On another note, Karin explores the 3D printer for several user cases (B8). Here she both involves learners in the design process itself and probes how certain tools of the makerspace could be included and make a difference in the preschool setting (fig. 3b). Like Kim in B15, Karin reflects on her personal development to dare and to persist whenever challenged: "One of my strengths is that I very rarely give up, but instead I just want things to work out" (B8). Several maker pedagogues show passion for getting involved with projects from the start, others show personal growth by building up passion during the process. Concluding, Anette describes the importance of reflective practice and their role in leading by example (B11): "We ultimately work with this to impact others, inspired by the learning environments we create. The children and us get to meet and use the materials in different contexts, but in my opinion there must be an interest from educators and will to explore and challenge, both themselves and the environment they act within. Here, the task for us as maker pedagogues is that we 'lead by example'".

\subsection{Play}

In the material we collected are multiple instances of play and playful experimentation present. In WS1 the pedagogues describe that they in their role test boundaries and try out new things. Maker pedagogue Karin presents and shares many different ideas that she tried out even though some of them turn out to be less successful. Playfulness can entail for example to be a co-creator of something that the learner(s) are making or exploring [such as the green screen in fig. 4b]. In a playful manner trying out things with the learners and add to the process without disturbing the maker-process. The robot project [fig. 1c and 1d] for example grew to include more learners. Playing even continued with the robot after they had concluded the project itself, instead it was a part of everyday play. In one of the blog posts (B8), Karin shares how the creation of 3D printed connectors of wooden train systems sparked playful interactions [fig. 4a]. Here the learners acted as 


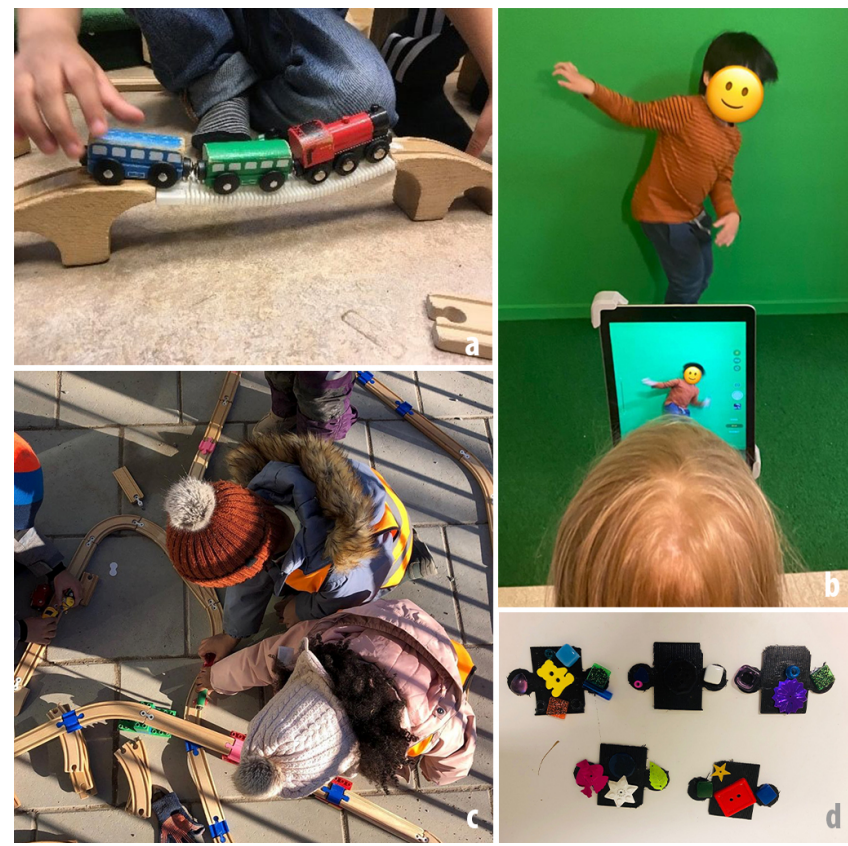

Figure 4: Examples of play and playfulness: (a) 3D printed connectors for more open play (b) Testing the green screen and playful exploration of provided technology (c) Playful worlds where otherwise closed materials meet through $3 \mathrm{D}$ printed connectors (d) Results of learners who were creatively making use of filament leftovers.

co-designers, where Karin helped printing materials to connect different materials with another, the project developed and progressed through interaction fueled by intense play [fig. 4c]. Even resulting 3D printing left-over material was used in a playful and creative manner [fig. 4d]. In another project with building robotic vehicles in LEGO Wedo (B12) Karin made room to act as a resource if needed and let learners find playful ways to succeed with their project on their own. Later, Stina reported from a different project in WS2, which aimed at learners exploring the skin of their bodies, but they instead started to investigate and playfully explore other things than their hands such as the materials, the equipment and other body - which the maker pedagogue described as an overall chaotic situation. Through her reflection, we see maker pedagogues then together discuss strategies, such as giving playful freedom to explore before starting with specific projects. Through play and playfulness maker pedagogues describe that they can reach their colleagues easier and work collaboratively by including more and more maker practices in their preschools.

\subsection{Two additional P's: Places and Presentation}

The physical makerspace, its design and resources made way for the maker pedagogues to see the possibilities that these learning environments provide. In one of the blog posts (B11), a learner describes the makerspace as "headquarters" - as an originating place, to which both learners and pedagogues return to, collect resources and see as their base [see fig. 5a]. Moreover, pedagogues report on

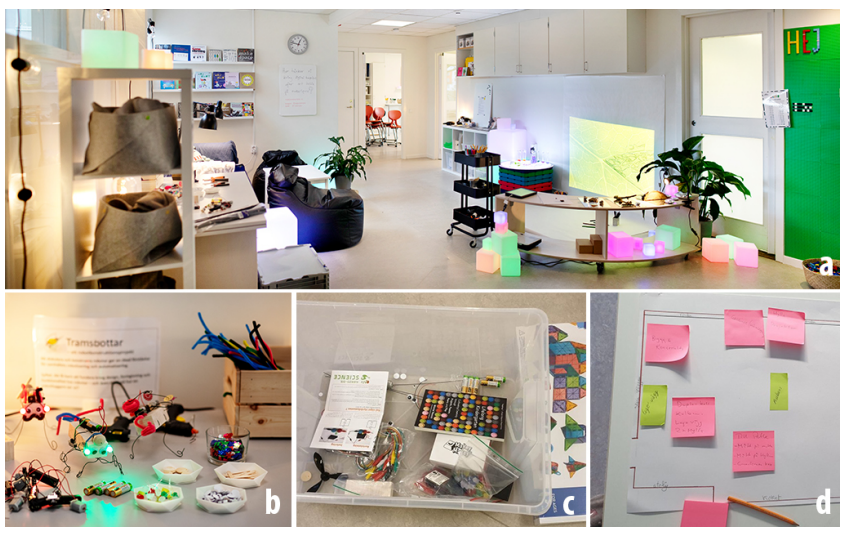

Figure 5: (a) Importance of place and presentation: The physical makerspace as nod, headquarter and place of inspiration (b) Adequately presenting to both learners and their teachers (c) The maker starter-kit (d) Planning a place for making in a preschool unit.

the importance of creating physical learning environments inspired by the makerspace in their own units [fig. 5d]. Place is key in terms of what it physically provides - that is machinery, materials and tools of making - but also about what it represents. Also, the digital space is as important as it serves as places to document and reflect the ongoing activities and builds a community to share knowledge and inspire each other as well as outreach to the wider public. We however stress the importance of a functioning organization, with a supportive infrastructure and a flexible and responsive organisation to make things happen. As Karin in B2 describes, a makerspace should be "a resource to use where the space, competence and material are already in place". Furthermore, when the maker pedagogues started their training, the managing team put together maker kits for them to dive right into their own experiments [fig. 5c]. We discovered that the maker pedagogues thrive through a desire to discover, to dare and to find their own individual path into making. To accommodate this approach requires more than reading, it requires hands-on exploratory projects, as well as play and tinkering with the material provided. The kit included material that was: open, adaptable, where one can make use of directly or in parts, as well as reusable and hack-able. In the empirical material, we saw how important the material and its adequate presentation is for the maker pedagogues [such as in fig. 5b]. An example are the LEGO walls that have been introduced in nearly all the partaking preschools by now. The maker pedagogues shared reflections on reasons to make instances of creative learning a success, where presentation is key - which put a lot of attention on level of preparation, the type and the amount of materials used, the skills of the learners involved as well as the importance to design for openness and potential to further grow and develop.

\section{DISCUSSION}

This paper addresses making in preschool education and what it might entail to become a maker pedagogue, by analysing how a group of nine pedagogues reflect about their practice. 
We argue that the municipality makerspace as initiator is an important node in this work that creates opportunities for the maker pedagogues to participate and form a community. Design principles of low floors, wide walls and high ceilings [45] are applied in the pedagogue's work and we can see how important these principles are to grow and to nurture a maker mindset. Here, activities done in the makerspace are constructed to include and open up for participation despite the level of knowledge in handling digital devices and experience aesthetics activities such as craft, while furthering computational thinking.

\section{Becoming a maker pedagogue}

Developing a maker mindset entails openness, curiosity, responsiveness, being a co-creator and the willingness to make use of technology and materials in preschool teachers' daily professional practice, which is key towards becoming a maker pedagogue. Sharing is connected to openness towards peers (both colleagues and learners) and the openness we see in the material is connected to what they are willing to discuss as failures. Curiosity is also connected to the willingness to try out new materials and allow the work to be an ongoing process. Using Resnick's four P's [45] as a framework for analysis we noticed that the projects foremost derive and build on interest and engagement from 'the learners'. The learners are, in this case, both the children and the pedagogues. This inquiry needs to stem from a bottom-up approach and include responsiveness to the endeavor. Resnick points out that passion and peers need to be brought together informally and around shared interests. Overall, we highlight three levels of peer-learning, here we argue that the maker pedagogue is a co-creator and has a responsiveness to peers, materials and the situation at hand. In addition to the four original P's: Projects, Peers, Passion and Play, we see how Places and Presentation contribute to a more situated understanding of creative learning. A way forward for early childhood education in developing children's digital literacy $[32,34,50]$ is to work with and develop a maker mindset. We argue that the makerspace is a place for this mindset to develop in an interactive and process-oriented manner where maker pedagogues - together with learners - explore new tools, create learning environments, work in projects that include passion and play and possibly influence views on the future were technology is even more accessible.

\section{Opportunities and Challenges}

When looking back at the workshops held, they act as a think tank for the pedagogues to reflect upon their own maker activities. The maker pedagogues talk about their own maker activities intertwined with the learners and can not be separated. There are instances where maker pedagogue reflect about how to make activities more including. In the blog posts we found success stories as well as less successful projects, key towards a maker mindset is to willingly and openly to reflect, hence seeing making as a learning process rather than an end-project. In this sense the blog and the workshops are tools in constant flow and present the 'little things' in the practice which reflects maker activities on a daily basis. In some of the projects we discussed, material was foremost used 'uncoded' and open where the learner had a strong agency to form the material after personal interest. When using a resource that is more coded (such as ready-made kits or learning material), it has a stronger agency and might steer the activity rather than build on engagements from learners. This aspect of coded and uncoded material needs to be investigated further, as materiality and resources are crucial for making, which also impacts teaching and learning processes. The maker pedagogues are passionate about their mission to transform their units and introduce making to their colleagues. Despite that, there is a challenge for the pedagogues to express what they are doing and talk about their professional development. We do notice a move toward more explicit ways of talking about their work from the first to the second workshop. Further we noted that maker pedagogues with time become schooled in verbalizing their way of working in a more distinct way.

\section{Towards building similar spaces and communities}

The requirements profile of a maker pedagogue has developed over time and is in this sense an ongoing process. At first, there was a focus among the decision makers that selected teachers should be interested in ICT and preschool digitalization, but over time, the focus and emphasis has landed in general pedagogical curiosity, a drive for personal development and a willingness to serve and support others. The last aspect is something of a balancing act, as the maker educators usually get access to machines, resources and a mindset that few preschool educators have a chance to get acquainted with. What the maker pedagogues must deal with is the bi-modal movement of simultaneously rushing forward, learning completely new skills and knowledge in maker practices but never losing their footing and forgetting their colleagues' starting point, which demands openness. Here we see a gap between maker pedagogues' own mission and their colleagues' needs. We argue therefore that curiosity, willingness and empathy can be more important abilities of maker pedagogues than just prior knowledge in ICT. To scale and share the maker pedagogue's mindset and their knowledge with peers outside the group is a challenge for the organisation, hence from an organizational perspective, we notice responsiveness. Therefore, we see that municipality makerspaces in the long haul face problems with issues of generalizability, scalability and sustainability. Here [5] suggest a continuous dialogue by addressing makerspaces as learning environments, the use of a maker frame to implement curriculum and using design-based research methodology that links practitioners work with empirical research. To scale up and spread the maker mindset further is a challenge and question remains to what extent it is possible and even desirable. We argue that a makerspace as a resource and the development of a maker mindset as presented in this study, could be a fruitful addition to preschool curriculum to address the demands that digitalisation and new material literacies present to early childhood education.

\section{CONCLUSION}

We noticed that working with a maker mindset demands a lot of the individual preschool teacher. In the process of becoming a maker pedagogue, they need to learn new things and engage both colleagues and learners. Tensions between a maker mindset and institutions occurs, as planned activities might collide with a maker mindset which is built on a bottom-up rather than a top-down 
approach. We see how frameworks around creative learning and the competences that new materials and tools require, impact how future-oriented educators need a way to work and navigate the fast-paced technological development and work towards a continuous professional development. Hence with this paper, we have contributed with input on what it entails to become a maker pedagogue, that opens for reflections on how to design and built for environments of creative - and hands-on - learning. By focusing on the journey and development this group of maker pedagogues in preschool settings take, and by highlighting some of the projects and problems they tend to, we argue that our work contributes to ongoing discussions that the FabLearn and MakeEd communities care for. Finally, a concern and a suggestion for future research is to investigate how pedagogues engage and how their responsiveness is expressed in the interaction with the learners at the preschools.

\section{ACKNOWLEDGMENTS}

We would like to thank the group of maker pedagogues that shared their experiences with us and let us be part of their inspiring transformation. We also thank the reviewers for their insightful input.

\section{REFERENCES}

[1] Yasemin Allsop. 2019. Assessing computational thinking process using a multiple evaluation approach. International fournal of Child-Computer Interaction 19 (March 2019), 30-55. https://doi.org/10.1016/j.ijcci.2018.10.004

[2] Lorenzo Angeli, Francesca Fiore, Alberto Montresor, and Maurizio Marchese. 2019 Designing a Hands-on Learning Space for the New Generation. In Proceedings of the FabLearn Europe 2019 Conference (FabLearn Europe '19). Association for Computing Machinery, New York, NY, USA, 1-3. https://doi.org/10.1145/3335055. 3335060

[3] Sara Aronin and Kim K. Floyd. 2013. Using an iPad in inclusive preschool classrooms to introduce STEM concepts. Teaching Exceptional Children 45, 4 (2013), 34-39. Publisher: SAGE Publications Sage CA: Los Angeles, CA.

[4] Dorit Assaf, Josef Buchner, and Andreas Jud. 2019. Evaluating a Makerspace Visiting Program for Schools at a University of Teacher Education. In Proceedings of the FabLearn Europe 2019 Conference (FabLearn Europe '19). Association for Computing Machinery, New York, NY, USA, 1-3. https://doi.org/10.1145/3335055. 3335057

[5] Sandra Becker and Michele Jacobsen. 2020. Becoming a Maker Teacher: Designing Making Curricula That Promotes Pedagogical Change. Frontiers in Education 5 (2020). https://doi.org/10.3389/feduc.2020.00083 Publisher: Frontiers.

[6] Matthew Berland. 2016. Making, tinkering, and computational literacy. Makeol ogy: Makers as learners 2 (2016), 196-205.

[7] Marina Umaschi Bers, Louise Flannery, Elizabeth R. Kazakoff, and Amanda Sullivan. 2014. Computational thinking and tinkering: Exploration of an early childhood robotics curriculum. Computers \& Education 72 (March 2014), 145-157. https://doi.org/10.1016/j.compedu.2013.10.020

[8] Bronwyn Bevan, Joshua Gutwill, Mike Petrich, and Karen Wilkinson. 2015. Learning Through STEM-Rich Tinkering: Findings From a Jointly Negotiated Research Project Taken Up in Practice. Science Education 99 (Jan. 2015). https: //doi.org/10.1002/sce.21151

[9] Paulo Blikstein, Zaza Kabayadondo, Andrew Martin, and Deborah Fields. 2017. An Assessment Instrument of Technological Literacies in Makerspaces and FabLabs: Assessment of Technological Literacies in Makerspaces and FabLabs. Fournal of Engineering Education 106, 1 (Jan. 2017), 149-175. https://doi.org/10.1002/jee. 20156

[10] Paulo Blikstein and Dennis Krannich. 2013. The Makers' Movement and FabLabs in Education: Experiences, Technologies, and Research. In Proceedings of the 12th International Conference on Interaction Design and Children (IDC '13). ACM, New York, NY, USA, 613-616. https://doi.org/10.1145/2485760.2485884

[11] Leanne Bowler. 2014. Creativity through" maker" experiences and design thinking in the education of librarians. Knowledge Quest 42, 5 (2014), 58-62.

[12] Marleny Luque Carbajal and M. Cecília C. Baranauskas. 2020. Analyzing the socioenactive dimensions of creative learning environments with preschool children. In Proceedings of the 19th Brazilian Symposium on Human Factors in Computing Systems (IHC '20). Association for Computing Machinery, New York, NY, USA, 1-10. https://doi.org/10.1145/3424953.3426510

[13] Daniel Cermak-Sassenrath and Emilie Møllenbach. 2014. Teaching to Tinker: Making As an Educational Strategy. In Proceedings of the 8th Nordic Conference on Human-Computer Interaction: Fun, Fast, Foundational (NordiCHI '14). ACM, New York, NY, USA, 789-792. https://doi.org/10.1145/2639189.2654827

[14] Sharon Lynn Chu, Genna Angello, Michael Saenz, and Francis Quek. 2016. Fun in Making: Understanding the experience of fun and learning through curriculum-based Making in the elementary school classroom. (2016). https://www.google.se/search?q=Fun+in+Making\%3A+ Understanding+the+experience+of+fun+and+learning+through+curriculumbased+Making+in+the+elementary+school+classroom\&oq=Fun+in+Making\% $3 \mathrm{~A}+$ Understanding+the + experience + of + fun + and +learning +through + curriculum-based+Making+in+the+elementary+school+classroom\&aqs= chrome..69i57.1696j0j1\&sourceid=chrome\&ie=UTF-8

[15] Susan Crichton. 2014. Leapfrogging Pedagogy: A Design Approach to Making Change in Challenging Contexts. Electronic Journal of e-Learning 1 (2014), 3-13.

[16] Árni Már Einarsson and Morten Hertzum. 2019. Scaffolding of Learning in Library Makerspaces. In Proceedings of the FabLearn Europe 2019 Conference (FabLearn Europe '19). Association for Computing Machinery, New York, NY, USA, 1-8. https://doi.org/10.1145/3335055.3335062

[17] Eva Eriksson, Carl Heath, Peter Ljungstrand, and Peter Parnes. 2018. Makerspace in school-Considerations from a large-scale national testbed. International journal of child-computer interaction 16 (2018), 9-15.

[18] Jean Griffin, Eliot Kaplan, and Quinn Burke. 2012. Debug'ems and other Deconstruction Kits for STEM learning. In Integrated STEM Education Conference (ISEC), 2012 IEEE 2nd. 1-4. https://doi.org/10.1109/ISECon.2012.6204168

[19] Erica Rosenfeld Halverson and Kimberly Sheridan. 2014. The Maker Movement in Education. Harvard Educational Review 84, 4 (Dec. 2014), 495-504. https: //doi.org/10.17763/haer.84.4.34j1g68140382063 Publisher: Allen Press.

[20] Carina Hermansson and Christina Olin-Scheller. 2019. Digi-läsning : Om läsning, kropp och rum i en digitaliserad förskola. Natur och kultur, 74-93. http: //urn.kb.se/resolve?urn=urn:nbn:se:kau:diva-71691

[21] Mikkel Hjorth, Rachel Charlotte Smith, Daria Loi, Ole Sejer Iversen, and Kasper Skov Christensen. 2016. Educating the Reflective Educator: Design Processes and Digital Fabrication for the Classroom. In Proceedings of the 6th Annual Conference on Creativity and Fabrication in Education (FabLearn '16). Association for Computing Machinery, New York, NY, USA, 26-33. https: //doi.org/10.1145/3003397.3003401

[22] Margaret Honey and David E. Kanter (Eds.). 2013. Design, Make, Play: Growing the Next Generation of STEM Innovators (1 edition ed.). Routledge, New York, NY

[23] Rose Johnson, Venus Shum, Yvonne Rogers, and Nicolai Marquardt. 2016. Make or Shake: An Empirical Study of the Value of Making in Learning about Computing Technology. In Proceedings of the The 15th International Conference on Interaction Design and Children (IDC '16). Association for Computing Machinery, New York, NY, USA, 440-451. https://doi.org/10.1145/2930674.2930691

[24] Yasmin Kafai, Chris Proctor, and Debora Lui. 2019. From Theory Bias to Theory Dialogue: Embracing Cognitive, Situated, and Critical Framings of Computational Thinking in K-12 CS Education. In Proceedings of the 2019 ACM Conference on International Computing Education Research (ICER '19). Association for Computing Machinery, New York, NY, USA, 101-109. https://doi.org/10.1145/3291279.3339400

[25] Yasmin Kafai and Mitchel Resnick. 1996. Constructionism in Practice: Designing, Thinking, and Learning in a Digital World. Lawrence Erlbaum Associates, Mahwah, NJ. https://www.routledge.com/Constructionism-in-Practice-DesigningThinking-and-Learning-in-A-Digital/Kafai-Resnick/p/book/9780805819854

[26] Yasmin B. Kafai. 2018. Building a Home for the Maker Movement. Fournal of Digital Learning in Teacher Education 34, 1 (Jan. 2018), 4-5. https://doi.org/10. 1080/21532974.2017.1398970

[27] William Kist. 2005. New literacies in action: Teaching and learning in multiple media. Vol. 75. Teachers College Press.

[28] Susanne Kjällander, Linda Mannila, Anna \AAkerfeldt, and Fredrik Heintz. 2021. Elementary Students' First Approach to Computational Thinking and Programming. Education Sciences 11, 2 (2021), 80. Publisher: Multidisciplinary Digital Publishing Institute.

[29] Torkel Klingberg. 2019. Matematik, arbetsminne och digital träning i förskoleklass. In Digitalisering i förskolan på vetenskaplig grund, Susanne Kjällander and Bim Riddersporre (Eds.). Natur och kultur, 74-93. http://urn.kb.se/ resolve?urn=urn:nbn:se:kau:diva-71691

[30] Stacey Kuznetsov, Piyum Fernando, Emily Ritter, Cassandra Barrett, Jennifer Weiler, and Marissa Rohr. 2018. Screenprinting and TEI: Supporting Engagement with STEAM through DIY Fabrication of Smart Materials. In Proceedings of the Twelfth International Conference on Tangible, Embedded, and Embodied Interaction (TEI '18). Association for Computing Machinery, Stockholm, Sweden, 211-220. https://doi.org/10.1145/3173225.3173253

[31] Sophie Landwehr Sydow, Jakob Tholander, and Martin Jonsson. 2017. "It's a Bomb!" - Material Literacy and Narratives of Making. In Proceedings of the 2017 CHI Conference on Human Factors in Computing Systems (CHI '17). ACM, New York, NY, USA, 121-132. https://doi.org/10.1145/3025453.3025529

[32] Colin Lankshear and Michele Knobel. 2012. 'New'literacies: technologies and values. Teknokultura. Revista de Cultura Digital y Movimientos Sociales 9 (Sept. 2012), 45-71

[33] Steen Lembcke, Michal Pilgaard, Mikkel Hjorth, Jerry Bak de Ridder, and Johannes Fibiger. 2018. Makerspaces in University Colleges: A Workshop About Maker 
Technologies and Design Thinking in Higher Education. In Proceedings of the Conference on Creativity and Making in Education (FabLearn Europe'18). ACM, New York, NY, USA, 114-115. https://doi.org/10.1145/3213818.3213843 eventplace: Trondheim, Norway.

[34] Jackie Marsh, Elizabeth Wood, Liz Chesworth, Bobby Nisha, Beth Nutbrown, and Bryony Olney. 2019. Makerspaces in early childhood education: Principles of pedagogy and practice. Mind, Culture, and Activity 26, 3 (July 2019), 221-233. https://doi.org/10.1080/10749039.2019.1655651 Publisher: Routledge aaaeprint: https://doi.org/10.1080/10749039.2019.1655651.

[35] Lee Martin. 2015. The promise of the maker movement for education. fournal of Pre-College Engineering Education Research (f-PEER) 5, 1 (2015), 4.

[36] Sylvia Libow Martinez and Gary S. Stager. 2013. Invent To Learn: Making, Tinkering, and Engineering in the Classroom. Constructing Modern Knowledge Press, Torrance, Calif.

[37] Iván Sánchez Milara, Kati Pitkänen, Arto Niva, Meguimi Iwata, Jari Laru, and Jukka Riekki. 2019. The STEAM path: building a Community of Practice for local schools around STEAM and Digital Fabrication. In Proceedings of the FabLearn Europe 2019 Conference (FabLearn Europe '19). Association for Computing Machinery, New York, NY, USA, 1-3. https://doi.org/10.1145/3335055.3335072

[38] Katerina Morfoniou, Iro Voulgari, Maria Sfyroera, and Dimitris Gouscos. 2020 Digital Games and the Emergence of Problem Solving Processes: a Case Study with Preschool Children. In International Conference on the Foundations of Digital Games (FDG '20). Association for Computing Machinery, New York, NY, USA 1-3. https://doi.org/10.1145/3402942.3402991

[39] Sean O'Brien, Alexandria K. Hansen, and Danielle B. Harlow. 2016. Educating Teachers for the Maker Movement: Pre-service Teachers' Experiences Facilitating Maker Activities. In Proceedings of the 6th Annual Conference on Creativity and Fabrication in Education (FabLearn '16). Association for Computing Machinery, New York, NY, USA, 99-102. https://doi.org/10.1145/3003397.3003414

[40] Kylie Peppler, Erica Halverson, and Yasmin B. Kafai (Eds.). 2016. Makeology (1 edition ed.). Routledge, New York.

[41] Íris Pereira, Altina Ramos, and Jackie Marsh. 2016. The Digital Literacy and Multimodal Practices of Young Children: Engaging with Emergent Research (2016), 247

[42] Sari Räisänen. 2015. Changing literacy practices : a becoming of a new teacher agency. University of Oulu.

[43] Mitchel Resnick. 2002. Rethinking learning in the digital age. Oxford University Press.

[44] Mitchel Resnick. 2014. Give P's a Chance: Projects, Peers, Passion, Play. (2014), 8.

[45] Mitchel Resnick. 2017. Lifelong Kindergarten: Cultivating Creativity through Projects, Passion, Peers, and Play. The MIT Press, Cambridge, Massachusetts.

[46] David Roedl, Shaowen Bardzell, and Jeffrey Bardzell. 2015. Sustainable Making? Balancing Optimism and Criticism in HCI Discourse. ACM Trans. Comput.-Hum. Interact. 22, 3 (June 2015), 15:1-15:27. https://doi.org/10.1145/2699742

[47] David Scaradozzi, Laura Screpanti, Lorenzo Cesaretti, M. Storti, and Elena Mazzieri. 2019. Implementation and Assessment Methodologies of Teachers' Training
Courses for STEM Activities. Technology, Knowledge and Learning 24, 2 (June 2019), 247-268. https://doi.org/10.1007/s10758-018-9356-1

[48] Michael Schad and W. Monty Jones. 2020. The Maker Movement and Education: A Systematic Review of the Literature. Fournal of Research on Technology in Education 52, 1 (Jan. 2020), 65-78. https://doi.org/10.1080/15391523.2019.1688739 Publisher: Routledge _eprint: https://doi.org/10.1080/15391523.2019.1688739.

[49] Jill Scott and Karen Wohlwend. 2017. Bringing Maker Literacies to Early Childhood Education. 209-219.

[50] Julian Sefton-Green, Jackie Marsh, Ola Erstad, and Rosie Flewitt. 2016. Establishing a Research Agenda for the Digital Literacy Practices of Young Children: A White Paper for COST Action IS1410. https://plaka-logika.blogspot.com/2017/ 07/establishing-research-agenda-for 25 .html

[51] Kimberly Sheridan, Erica Rosenfeld Halverson, Breanne Litts, Lisa Brahms, Lynette Jacobs-Priebe, and Trevor Owens. 2014. Learning in the Making: A Comparative Case Study of Three Makerspaces. Harvard Educational Review 84, 4 (Dec. 2014), 505-531. https://doi.org/10.17763/haer.84.4.brr34733723j648u

[52] Skolverket. [n.d.]. Läroplan för förskolan, Lpfö 18. https://www.skolverket.se/ publikationsserier/styrdokument/2018/laroplan-for-forskolan-lpfo-18

[53] Emily Tam and Trudy-Ann Sweeney. 2016. Learning with iPads in Early Childhood Education. In Publishing Higher Degree Research: Making the Transition from Student to Researcher, Janice Orrell and David D. Curtis (Eds.). SensePublishers, Rotterdam, 43-52. https://doi.org/10.1007/978-94-6300-672-9 5

[54] Megan Tomko, Amanda Schwartz, Wendy Newstetter, Melissa Alemán, Robert Nagel, and Julie Linsey. 2018. "A Makerspace Is More Than Just a Room Full of Tools": What Learning Looks Like for Female Students in Makerspaces. American Society of Mechanical Engineers Digital Collection. https://doi.org/10.1115/ DETC2018-86276

[55] Dimitra Tsoumpri. 2019. Polargraph, the Project: Education through DIY. In Proceedings of the FabLearn Europe 2019 Conference (FabLearn Europe '19). Association for Computing Machinery, New York, NY, USA, 1-3. https://doi.org/10. ation for Computing $M$
$1145 / 3335055.3335076$

[56] Miki Vizner and Amanda Strawhacker. 2016. Curious Construction Kit: A programmable building kit for early childhood. In Proceedings of the 6th Annual Conference on Creativity and Fabrication in Education (FabLearn '16). Association for Computing Machinery, New York, NY, USA, 90-93. https://doi.org/10.1145/ 3003397.3003412

[57] Riina Vuorikari, Anusca Ferrari, Yves Punie, European Commission, and Joint Research Centre. 2019. Makerspaces for education and training: exploring future implications for Europe. http://publications.europa.eu/publication/manifestation identifier/PUB_KJNA29819ENN OCLC: 1127885227.

[58] Etienne Wenger-Trayner, Mark Fenton-O'Creevy, Christopher Kubiak, Steven Hutchinson, and Beverly Wenger-Trayner. 2014. Learning in Landscapes of Practice: Boundaries, identity, and knowledgeability in practice-based learning. Routledge, Abingdon. http://www.routledge.com/books/details/9781138022195/

[59] Mikael Wiberg, Hiroshi Ishii, Paul Dourish, Anna Vallg $\backslash a$ arda, Tobie Kerridge, Petra Sundström, Daniela Rosner, and Mark Rolston. 2013. Materiality matters-experience materials. interactions 20,2 (2013), 54-57. http: //dl.acm.org/citation.cfm?id=2427087 